Article

\title{
Estimating the Preservation Value of Wuyishan National Park from the Perspective of Bounded Rational Decision Making
}

\author{
Chang Liu ${ }^{1}$, Mingshui Lin ${ }^{1, * \mathbb{D}}$, Xinhua $\mathrm{Qi}^{2, *}$ and Wenjuan Zheng ${ }^{1}$ \\ 1 College of Tourism, Fujian Normal University, Fuzhou 350117, China; liuchang@fjnu.edu.cn (C.L.); \\ zwj_zju@163.com (W.Z.) \\ 2 School of Geographical Sciences, Fujian Normal University, Fuzhou 350117, China \\ * Correspondence: waterming2003@163.com (M.L.); fjqxh74@163.com (X.Q.); Tel.: +86-0591-22868726 (X.Q.)
}

check for

updates

Citation: Liu, C.; Lin, M.; Qi, X.; Zheng, W. Estimating the Preservation Value of Wuyishan

National Park from the Perspective of Bounded Rational Decision Making. Sustainability 2021, 13, 6983.

https://doi.org/10.3390/su13136983

Received: 5 May 2021

Accepted: 18 June 2021

Published: 22 June 2021

Publisher's Note: MDPI stays neutral with regard to jurisdictional claims in published maps and institutional affiliations.

Copyright: (c) 2021 by the authors. Licensee MDPI, Basel, Switzerland. This article is an open access article distributed under the terms and conditions of the Creative Commons Attribution (CC BY) license (https:/ / creativecommons.org/licenses/by/ $4.0 /)$.

\begin{abstract}
Simplifying and popularizing the preservation values (valuation methods) of national parks-based on the premise of accuracy—shows stakeholders the importance of national parks, and is the basis for exploring sustainable use and development mechanisms. However, there are hypotheses biases, strategic biases, and starting point biases in regards to the existing evaluation methods. Therefore, based on the results of the contingent valuation method of research, under bounded rationality, this study uses the two-stage dichotomous choice contingent valuation and selects three methods to estimate the willingness to pay (WTP) for preservation at Wuyishan National Park. The results support that the two-stage contingent valuation method could effectively evade uncertainty with a "willingness to pay" decision making under bounded rationality, and factually reflect the real WTP. The results show that: (1) the average willingness to pay (truncated) of each household in Wuyishan National Park is CNY 609 (USD 93.90), which is similar to the actual average tourism expenditure of each household. (2) The cultural worldviews and perceived restorative environment have significant impacts on willingness to pay. (3) Comparing the preservation value of Wuyishan National Park with the actual financial input plays a positive role in manifesting the importance of Wuyishan National Park and attracting more financial input. The preservation value of Wuyishan National Park in the key market is about six times that of the basic market and onethird of that in the national market, which provides a theoretical basis for selecting the key tourism development market of Wuyishan National Park. (4) Those respondents believe that more funds should be put into protecting the national parks for their sustainable existence and bequeathing to future generations, which shows that the construction of the national park system is significant in improving natural values. This study attempted to provide theoretical support for improving non-market value and sustainable development of national parks.
\end{abstract}

Keywords: DC-CVM; willingness to pay; preservation value; Wuyishan national park; China

\section{Introduction}

National parks, as typical natural reserves, are known for their public attributes of maintaining the integrity and authenticity of the natural ecosystem, as well as the biodiversity. They provide many non-market products and services in addition to market products [1,2]. The economic value of national parks consists of use and non-use value. In particular, non-use value, also known as preservation value, is the main component of economic value. It refers to the value that humankind is willing to pay for improving and protecting non-used resources, including option value, existence value, and bequest value. In the pure market environment, however, such value is difficult to be manifested [2]. As the national park system keeps refining, controversy follows, and how to estimate and manifest the preservation value of national parks in the context of an unbalanced relationship between humans and nature, and the surge of tourists, has become a focus of attention for government at all levels and academic circles [1-3]. 
Wuyishan National Park, as a world cultural and natural heritage site, is part of the first-batch of 10 pilot areas of the national park system in China. Its prominent preservation value lies in its mission of exploring the integrated development between the Chinese national park system and ecological conservation, public services, enterprise-universityresearch institute combination, and cultural tourism [4]. However, similar to other World Heritage Sites designated by the United Nations Educational, Scientific, and Cultural Organization (UNESCO), whose sustainability is not necessarily guaranteed [5-7], the Wuyishan National Park pilot area is featured by complex ownership of natural resources, a higher proportion of collective forest rights, high dependence of local villagers on natural resources, tea, and Moso bamboo, as traditional pillar industries and sharp contradictions between its protection and utilization. Meanwhile, natural disasters, climate change, urbanization, and surging tourists have intensified the pressure in protecting the national park $[2,8,9]$. In order to cope with the challenges, it is necessary to put into place a sound system of government financial input and social participation [10]. In this sense, the manifestation of the preservation value of national parks is beneficial to securing greater public financial input [2], deepening the public's awareness on the importance of the parks, promoting social participation, and further improving the funding system for maintenance [2,11-14].

In order to avoid or reduce the bias, the methods of value evaluation are becoming increasingly complex, leading to a decrease in their practicality, while not effectively avoiding the bias. Therefore, how to optimize the existing simple methods and reduce the bias, while ensuring their practicality, is the focus of value assessment methods. Based on bounded rational decision making, this study adopts a two-stage approach of valuation (DC-CVM), both in hypothetical and real settings, to estimate the preservation value of Wuyishan National Park and minimize the CVM evaluation error. The sociodemographic and psychological factors (cultural worldview and perceived restorative environment) that influence tourists' willingness to pay (WTP) are investigated and verified from respondents' psychological statuses, such as their worldview and their perceptions of the environment. The theoretical aim of this paper was to partially respond to the need for theoretical extension and development of the CVM method; to extend the applicability of the CVM method; and to provide new ideas for the theoretical exploration of CVM. The practical aim of this paper was to-objectively and accurately - evaluate the preservation value of Wuyishan National Park (its importance to stakeholders will be highlighted to enhance social participation and improve the funding system). In addition, the study attempts to confirm the universal applicability of CVM in evaluating the preservation value of national parks and, thus, provide scientific support to refine the national park system.

\section{Literature Review}

\subsection{The Bounded Rational Decision Making and CVM}

Bounded rational decision making refers to the fact that, when faced with a decision problem, the decision maker does not fully perceive the preference relationships among the alternatives in the solution set, and the perceived preferences are only a fraction of his or her actual preferences. It explains the complexity of the decision maker's mental activity and the limited nature of rational decision making when faced with a decision with incomplete information [15], pointing out that some of the decision maker's perceived preferences are even subconscious [16]. Therefore, CVM respondents are prone to systematically biased responses to WTP elicitation questions, when the questionnaire or interview situation has specific characteristics, and there is a lack of clear preferences between the market and environmental goods [17]. Existing studies in the literature have pointed out that the CVM method induces irrational response behavior of respondents and leads to bias [2,3,17].

\subsection{National Parks in China}

The China national park concept is based on ecosystem management, emphasizing ecosystem values, relying on ecological science and system planning, and valuing the 
cultural values of indigenous peoples and local residents attached to natural objects [18]. National parks have become a widely used model of protected areas, nature, and culture conservation around the world [19]; there are 10 approved pilot areas of the national park system in China (since 2016). As a major institutional innovation for the construction of ecological civilization and a powerful grip for the five-sphere integrated plan [20], national parks are attracting attention, and are the focus of extensive discussions among Chinese scholars, especially in terms of integrated management and evaluation of national parks [21]. For example, in the spatial management of national parks, the key to ecosystembased management is to ensure that ecosystems have the capacity to provide diverse services to promote human well-being in the long-term [22]. Relatively few studies have been conducted in China to assess the importance of national parks from the perspective of stakeholders' social choices $[4,21]$. It is important to achieve the goal of harmonizing and unifying the ecological conservation of China's national parks first, China's national representation, and the public welfare of all people, by visualizing the value of China's national parks to stakeholders [4].

\subsection{Valuation Methods for National Parks}

As research verifies the positive effect of the perceived preservation value on protection [23-25], evaluation of the preservation value of national parks and other ecological resources have attracted widespread attention [2]. How to simplify and popularize universal evaluation methods with minimized evaluation errors has always been the focus of attention in valuation studies [1]. It is noteworthy that, since the valuation of ecological resources is realized within the human-centered framework [1] when designing evaluation methods using economic theories, it is necessary to validate the role of human psychological status in the evaluation [1,2,12-14]. Therefore, valuation methods of national parks requiring the support of rigorous economic principles should not only be convenient and accurate, but also verify the role of psychological status in the evaluation. Currently, valuation is mainly conducted in three ways: market-based method, the revealed preference approach, and stated preference worldwide [26]. The preservation value of national parks, restricted by non-market characteristics of environment and services [26], is mainly estimated through stated preference [1]. Specifically, the most widely employed is the contingent valuation method (CVM) [2,3,27], which sets a hypothetical market and uses the theory of utility maximization to estimate respondents' willingness to pay (WTP), and then evaluates the preservation value [28]. CVM can be open or closed, with the latter represented by single-bounded dichotomous choice (DC) CVM. It is widely applied to the valuation of ecological resources, such as national parks [2], natural or cultural tourism resources $[12,29,30]$, and ecological tourism resources [27,31], with flexible elicitation and effective information acquisition, as respondents only get to choose "yes" or "no" for the given amount of payment, which is quite similar to decision making in the realistic market trading. In order to avoid starting-point bias, strategic bias, and positivity bias arising from single-bounded DC-CVM, double-bounded and multi-bounded DC-CVM have been developed one after another, but it remains impossible to eradicate strategic bias and anchoring effects. Moreover, as boundaries increase, statistical analysis models get increasingly more complicated. In this regard, some scholars have adopted choice experiment (CE) to explore WTP for ecological compensation and preference [32-34]. However, in addition to the defects of vague preference, difficult cognition, and burdened perception of respondents, complex research, and high cost, CE still fails to eliminate CVM bias and even suffers metric bias [35].

To date, all studies adopting CVM to estimate WTP have assumed that reasonable WTP decisions made by respondents are sound. However, in the realistic decision-making setting, economic agents are limited in cognitive ability, which prevents them from making perfectly rational decisions according to standard economic models. Their WTP decision making is actually bounded rational decision, subjected to the impact of individual bounded cognition and investigation environment, causing uncertainty in respondents in 
their WTP decision making. This is one of the underlying reasons behind CVM bias. Frör proposed this idea in 2018, and empirically demonstrated that respondents were subjected to the effect of bounded rational cognition for WTP decision making. The more prudent the respondents, the lower starting-point bias under DC-CVM. It proved that starting-point bias, which does not belong to the characteristic bias of single-bounded DC-CVM, was determined by the cognitive disposition of respondents [17]. CVM question design should allow respondents to take WTP into full consideration, and induce them to express genuine WTP under perfect rationality to avoid bias [14]. According to the principles put forward by the valuation panel of the U.S. National Oceanic and Atmospheric Administration [36], two-stage DC-CVM with hypothetical and real settings can be constructed to minimize the bias with single-bounded DC-CVM, guide respondents to input more cognitive resources, avoid the complexity of multi-bounded DC-CVM and CE, and induce respondents to express their genuine WTP [37]. While confirming the high validity of DC-CVM, prior studies employing DC-CVM to evaluate the preservation value of such tourism resources, such as Grand Canal [12], Hallyu [30], Dokdo [38], harbor seals [39], and Li River [3], clarified the influence of demographic and psychosocial characteristics on WTP of tourists.

\subsection{Cultural Worldview and Restorative Environmental Perception}

Today, all the valuation methods are based on human preference, and previous studies have also shown that, besides demographic characteristics, psychological factors also play an important role in influencing WTP [12,31]. The "habitus and field" theory of Pierre Bourdieu stated that when one's habitus fits a field, he or she will perfectly agree with the environment; otherwise, he or she will feel unaccustomed. The cultural worldview of Chinese people is personal cultural cognition, with Chinese culture attributes formed in Chinese culture socialization. It is anticipated that the abundant cultural and historical resources in Wuyishan National Park will affect the protection behavior (WTP) of tourists [40]. Meanwhile, it can be anticipated that when tourists recognize the beneficial effect of the national park environment for physical and mental restoration, their perceived restorative environment will affect protection behavior (WTP) [41]. Therefore, considering the interaction between the tourism environment in Wuyishan National Park and tourists, this study selects cultural worldview or "degree of internalization of traditional culture" to represent "habitus", and perceived restorative environment or "degree of perception on environment promoting physical and mental restoration" to represent "field", aiming to identify the psychological status of respondents when they traveled in Wuyishan National Park.

Cultural worldview refers to one's subjective cognition, understanding, and statement of a culture he or she encounters based on his or her (own) worldview [42]. Cultural worldview is neither improvised nor shaped in a short period of time, but is a kind of consciousness developed during the socialization of culture. As a type of personal worldview, it does not have to be shared or aligned with others [43]. Choi et al. developed a cultural worldview scale for measuring the individual degree of perception on cultural value in line with psychological attitudes, adding a new dimension for understanding cultural worldview [44]. The scale is not only used to assess individuals' underlying general attitudes towards culture, but is also widely used to discuss tour experience and investigate cultural value [40].

The perceived restorative environment has been broadly adopted in studies on cognitive, emotional, spiritual, and physical restoration [45-47], and closely followed by scholars in the fields of tourism and leisure and psychology. It is now proven to play an important role in interpreting modern slow travel experience [48-50].

\section{Methods}

\subsection{Overview of the Research Area}

Wuyishan National Park, sitting in the north of Fujian Province in China, consists of Wuyishan National Nature Reserve, Wuyishan National Scenic Spot, and Jiuqu Upper Reach Protected Zone, covering an area of up to $1001.41 \mathrm{~km}^{2}$. In 1987, Wuyishan was 
included in the international Man and the Biosphere reserve network, and it is one of the 39 mixed World Heritage Sites. Wuyishan National Park is a key area for global biodiversity protection, boasting the most complete, typical, and largest mid-subtropical primary forest ecosystem over the same latitude globally. Meanwhile, Wuyishan is rich in cultural and ecological value, as it is the basis for the world to study Zhu Xi's Neo-Confucianism, and even oriental culture, the birthplace of cliff coffin, the cradle of the world black tea culture, and the starting point of China's ancient Tea Road. On this account, Wuyishan National Park is an ideal case for discussing the preservation value of national parks. The famous landscapes of Wuyishan National Park are shown in Figure 1.
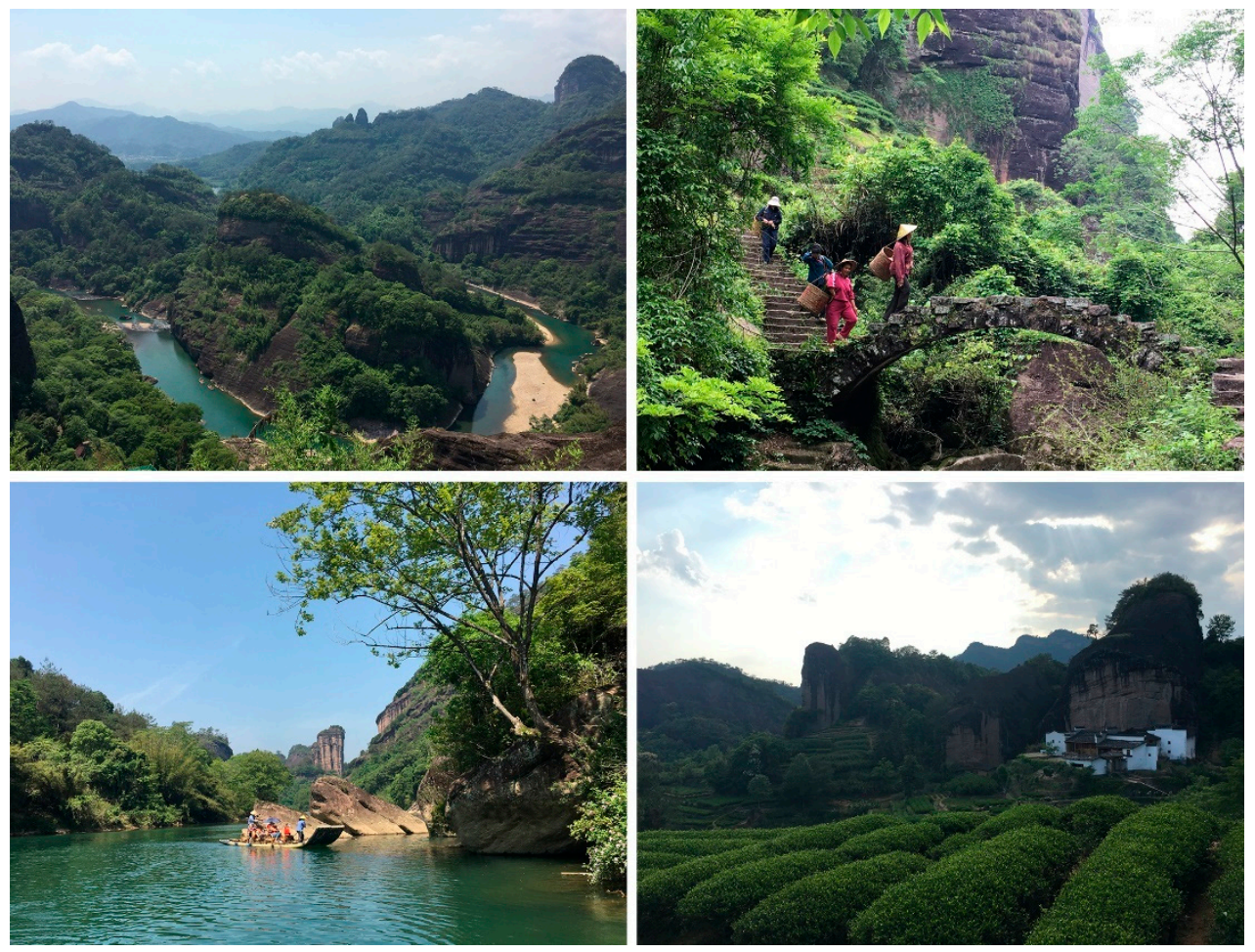

Figure 1. Scenic views of Wuyishan National Park. Source: author, 2021.

\subsection{Modeling}

The study used DC-CVM to give respondents a random payment amount, collect their WTP, and convert the WTP into a probabilistic model to estimate WTP functions [1,2]. The respondents' choice on whether or not to pay a fund was based on utility maximization. When the respondents chose to pay the randomly given amount, their utility function was $v(1, \mathrm{Y}-\mathrm{A} ; \mathrm{s})$; when they chose not to pay the amount, their utility function was $v(0, \mathrm{Y} ; \mathrm{s})$. Consequently, as shown in Formula (1), utility ( $v 1)$, when the respondents were willing to pay the randomly given amount and preserve Wuyishan National Park was equal to or greater than utility $(v 0)$, when they were unwilling to pay the preservation fund, and give up preserving the national park.

$$
v 1(1, \mathrm{G}-\mathrm{A} ; \mathrm{s})+\varepsilon 1 \geq v 0(0, \mathrm{G} ; \mathrm{s})+\varepsilon 0
$$

where $v=$ indirect utility function; $G=$ income; $v 1=$ pay the preservation fund of CNY A to preserve Wuyishan; $v 0=$ not pay CNY A to give up preserving Wuyishan; $\mathrm{s}=$ independent variable (e.g., cultural worldview, perceived restorative environment, gender, age and education); $\varepsilon 1,0=$ random variable averaged at 0 .

A Logit model is used to estimate WTP, because in the utility difference $(\Delta v)$ for choosing (or not) to preserve Wuyishan National Park, even if the willingness to pay the preservation fund of CNY A is affected by other factors, choosing (or not) to preserve 
Wuyishan remains categorical data. Based on the Logit model and the utility theory, the probability (P1) of participating in the preservation of Wuyishan National Park is expressed in Formula (2).

$$
\mathrm{P} 1=\mathrm{F} \eta(\Delta v)=\frac{1}{1+\beta^{\Delta v}}=\frac{1}{1+\beta^{-(\alpha+\beta \ln A+\gamma \ln Y)}}
$$

where $\mathrm{F} \eta=$ cumulative distribution function of standard logistic variate; $\alpha=$ constant; $\beta=$ coefficient of the given amount; $\gamma=$ coefficient of independent variable; $Y=$ independent variable.

Maximum likelihood estimation is applied to evaluate the Logit model. According to the methods of estimating WTP proposed by Henemann [17], and in the combination of Formula (2), WTP can be estimated in three ways. The first is WTP means, as shown in Formula (3).

$$
\text { Mean }(\mathrm{WTP})=\int_{0}^{\infty}(\Delta v) d A=-\frac{1}{\beta_{1}} \ln [1+\exp (\alpha)]
$$

where $\alpha=$ constant; $\beta$ = coefficient of the given amount.

The second is the overall mean, as shown in Formula (4).

$$
\text { Overall mean }(\mathrm{WTP})=\int_{0}^{\infty} F_{\eta} d B-\int_{0}^{\infty}\left(1-F_{\eta}\right) d B
$$

The third is WTP truncated, as shown in Formula (5). This is the only method that satisfies consistency of theory constraints, statistical validity, and aggregation capability to the greatest extent [36].

$$
\text { Truncated (WTP) }=\int_{0}^{\operatorname{Max} \cdot A} F_{\eta}(\Delta v) d A=-\frac{1}{\beta_{1}} \ln \left[\frac{1+\exp (\alpha)}{1+\exp \left(\alpha^{*}+\beta_{1}+\operatorname{Max} \cdot A\right)}\right]
$$

where $\alpha=$ constant; $\beta=$ coefficient of the given amount.

\subsection{DC-CVM Question Design}

This study designed the following virtual scripts containing basic information about Wuyishan to guide the respondents to determine their WTP for the preservation value of Wuyishan:

"Wuyishan National Park is the only "world heritage-mixed property" in China with its well-preserved primary forest ecosystem, abundant species resources and unique Danxia landform. Known as a famous historical and cultural mountain of three religions, Wuyishan has been the habitat of the spiritual practice life since the Qin and Han dynasties, and was once a place where Confucian Lectures were held. With the gradual increase in tourism demand, the human ecological system of the national park represented by Wuyishan is subjected to severe tests. If the culture, history, and ecology of Wuyishan are damaged due to insufficient care and exploitation errors. It is value will probably vanish. Simultaneously, the lack of traditional moral and cultural education has also resulted in the social problem of egoism. Wuyishan National Park is more than a beautiful natural scenery; it is an essential place for the education of traditional virtues, etiquette, and philosophy. Consequently, it is needed to recognize its value, protect every inch of this place and pass on the traditional virtues of the Chinese nation to the descendants through Wuyishan. Furthermore, as the common natural and cultural heritage of humanity on behalf of China, Wuyishan needs us to protect and manage it in a more actively way."

The core of the question design is to identify the reasonable WTP for non-use value of Wuyishan National Park, but as previously discussed, bias tends to be observed in the hypothetical setting. In response, the real setting is added after the basic hypothetical setting to minimize bias (as shown in Table 1) [3,51]. 
Table 1. The two-stage question design.

\begin{tabular}{|c|c|}
\hline Stage & Contents \\
\hline First stage & $\begin{array}{l}<\text { Question } 1>\text { Would you be willing to pay CNY __ (only once) as the } \\
\text { preservation fund collected from each household to ensure the long-term } \\
\text { preservation of Wuyishan National Park, a World Cultural and Natural } \\
\text { Heritage Site? } \\
\begin{array}{lll}\text { (1) Yes } & \text { (2) No Please start with Question } 3\end{array}\end{array}$ \\
\hline Second stage & $\begin{array}{l}<\text { Question 2> (In the case of "Yes" to Question 1) Would you be willing } \\
\text { to activate an automatic debit service or WeChat timed transfer to ensure } \\
\text { the collection of your donation without considering the capital risk? } \\
\begin{array}{lll}\text { (1) Yes } & \text { (2) No }\end{array}\end{array}$ \\
\hline
\end{tabular}

The first stage (hypothetical setting): in order to evaluate the preservation value of Wuyishan National Park, the study set up the hypothetical setting with dichotomous choice questions. An open-ended pre-investigation was conducted among 60 respondents to identify the specific payment amount of A. According to the results of the pre-investigation, the amount ranged between CNY 0 and 2000 (USD 308.20), and the given payment amount was eventually identified at six levels (USD 7.7 (CNY 50), USD 15.4 (CNY 100), USD 30.8 (CNY 200), USD 46.2 (CNY 300), USD 77 (CNY 500), USD 154.1 (CNY 1000)), based on frequency analysis and interviews. In the official investigation, the respondents were only asked to choose if they were willing or unwilling to pay the randomly given amount for preserving Wuyishan National Park. In the valuation of Wuyishan through questionnaires, how to inform the respondents of the purpose of use of the payment amount, in simple and clear ways, seemed crucial. In order to minimize strategic bias, the purpose of use of the payment amount was expressed as "preservation fund of Wuyishan National Park".

The second stage (real setting): the real setting, closer to the realistic WTP decisionmaking setting, was placed to further guide the respondents to express their genuine WTP. If they chose to pay in the hypothetical setting, but not to pay in the real setting, it was concluded that the respondents did not indicate their genuine willingness.

\subsection{Scale Selection and Results of Exploratory Factor Analysis}

In reference to the cultural worldview scale used by Kang et al. [40], the study selected eight questions in two dimensions (importance of culture, familiarity with traditional cultural symbols) of cultural worldview. By referring to scales on perceived restorative environment by Hartig et al. [48] and Laumann et al. [49] and combining the research subject, it chose 12 questions in three dimensions, including exploration and discovery, landscape structure, and away from daily life. A five-point Likert scale $(1=$ strongly disagree, 2 = disagree, $3=$ neutral, $4=$ agree, $5=$ strongly agree) was adopted (as shown in Table 2).

\subsection{Data Collection and Samples}

Questionnaires were distributed through simple random sampling to tourists who had visited Wuyishan National Park in the past year via the Credamo online platform, from April 10 to 26, 2020. The response was provided in the form of self-recording. Given the difficulty for those above age 60 in answering by themselves online, and their low participation in online investigation, the group was contacted in advance, offline, and trained investigators were designated to assist them in filling out the questionnaires. Among the 550 copies of collected questionnaires, 543 copies were valid, accounting for $98.7 \%$ of the total. The samples featured strong revisit intentions, with a balance between genders, different marital statuses, and a large proportion of young respondents. Tables 2 and 3 shows the statistics on variable input into the Logit model and the mean value. 
Table 2. An exploratory factor analysis of cultural worldview and perceived restorative environment.

\begin{tabular}{|c|c|c|c|c|c|c|}
\hline Concepts & Variables & Item & Factor Loading & Eigen Value & Cronbach's $\alpha$ & $\mathbf{M}$ \\
\hline \multirow{8}{*}{$\begin{array}{c}\text { Cultural } \\
\text { Worldview }\end{array}$} & \multirow{5}{*}{$\begin{array}{l}\text { Importance of } \\
\text { traditional } \\
\text { culture }\end{array}$} & Keep articles of traditional culture & 0.883 & \multirow{5}{*}{3.499} & \multirow{5}{*}{0.888} & \multirow{5}{*}{4.53} \\
\hline & & Protect cultural heritage & 0.863 & & & \\
\hline & & $\begin{array}{l}\text { Cultural heritage helps develop } \\
\text { national identity }\end{array}$ & 0.824 & & & \\
\hline & & Cultural heritage will vanish & 0.760 & & & \\
\hline & & $\begin{array}{c}\text { Cultural heritage has } \\
\text { special meanings }\end{array}$ & 0.773 & & & \\
\hline & \multirow{3}{*}{$\begin{array}{l}\text { Familiarity } \\
\text { with traditional } \\
\text { cultural } \\
\text { symbols }\end{array}$} & \multirow{3}{*}{$\begin{array}{l}\text { Know about traditional custom } \\
\text { Know about traditional costumes } \\
\text { Know about traditional diet made } \\
\text { by elder generations }\end{array}$} & 0.923 & \multirow{3}{*}{2.268} & \multirow{3}{*}{0.814} & \multirow{3}{*}{3.83} \\
\hline & & & 0.919 & & & \\
\hline & & & 0.619 & & & \\
\hline \multicolumn{7}{|c|}{${ }^{*}$ Cumulative $\%=72.1, \mathrm{KMO}=0.842$, Bartlett's Chi-Square $=2336.249(\mathrm{df}=28, p<0.000)$} \\
\hline \multirow{12}{*}{$\begin{array}{l}\text { Restorative } \\
\text { Environ- } \\
\text { mental } \\
\text { Perception }\end{array}$} & \multirow{5}{*}{$\begin{array}{l}\text { Exploration and } \\
\text { discovery }\end{array}$} & Know about Wuyishan & 0.815 & \multirow{5}{*}{3.41} & \multirow{5}{*}{0.892} & \multirow{5}{*}{4.43} \\
\hline & & Travel around Wuyishan & 0.800 & & & \\
\hline & & $\begin{array}{l}\text { Wuyishan is my favorite type of } \\
\text { scenic spots }\end{array}$ & 0.778 & & & \\
\hline & & $\begin{array}{c}\text { Wuyishan is worth exploring } \\
\text { and discovering }\end{array}$ & 0.735 & & & \\
\hline & & Wuyishan is fun & 0.734 & & & \\
\hline & \multirow{4}{*}{$\begin{array}{l}\text { Landscape } \\
\text { structure }\end{array}$} & $\begin{array}{l}\text { Wuyishan National Park is } \\
\text { in chaos }\end{array}$ & 0.906 & \multirow{4}{*}{3.357} & \multirow{4}{*}{0.93} & \multirow{4}{*}{3.38} \\
\hline & & $\begin{array}{c}\text { Wuyishan National Park } \\
\text { lacks order }\end{array}$ & 0.902 & & & \\
\hline & & $\begin{array}{c}\text { Wuyishan National Park } \\
\text { seems disorganized }\end{array}$ & 0.891 & & & \\
\hline & & Landscape is poorly structured & 0.842 & & & \\
\hline & \multirow{3}{*}{$\begin{array}{l}\text { Away from } \\
\text { daily life }\end{array}$} & Be free from the depressing reality & 0.829 & \multirow{3}{*}{2.369} & \multirow{3}{*}{0.845} & \multirow{3}{*}{4.08} \\
\hline & & Forget all about reality & 0.825 & & & \\
\hline & & Get out of the dull daily life & 0.804 & & & \\
\hline
\end{tabular}

${ }^{*}$ Cumulative $\%=76.1, \mathrm{KMO}=0.902$, Bartlett's Chi-Square $=4350.318(\mathrm{df}=66, p<0.000)$.

Table 3. Variable setting and description.

\begin{tabular}{|c|c|c|c|}
\hline Variables & $\mathbf{M}$ & S.E. & Remarks \\
\hline Revisit intention & 0.91 & 0.286 & $0=$ unwilling to, $1=$ willing to \\
\hline Gender & 0.44 & 0.497 & $0=$ male, $1=$ female \\
\hline Age & 2.71 & 1.073 & $\begin{array}{l}1=\text { aged below } 20,2=\text { aged } 21-30,3=\text { aged } 31-40 \\
4=\text { aged } 41-50,5=\text { aged } 51-60,6=\text { aged above } 60\end{array}$ \\
\hline $\begin{array}{l}\text { Monthly income } \\
\text { (per capita) }\end{array}$ & 3.37 & 1.322 & $\begin{array}{c}1=\text { less than CNY } 3000,2=\text { CNY 3000-4999, } \\
3=\text { CNY 5000-6999, 4 = CNY 7000-8999, } \\
5=\text { CNY 9000-11,999, } 6=\text { CNY 12,000, and above }\end{array}$ \\
\hline Education & 2.05 & 0.443 & $\begin{array}{c}1=\text { high school and below, } 2=\text { undergraduate (junior } \\
\text { college) and above, } 3=\text { postgraduate and above }\end{array}$ \\
\hline Marital status & 0.51 & 0.500 & $0=$ unmarried, $1=$ married \\
\hline Occupation & 3.69 & 1.758 & $\begin{array}{l}1=\text { student, } 2=\text { state-owned enterprise, } 3=\text { public } \\
\text { institution, } 4=\text { civil servant, } 5=\text { private enterprise, } \\
\qquad 6=\text { foreign enterprise, } 7=\text { freelancer }\end{array}$ \\
\hline
\end{tabular}

\section{Results}

\subsection{WTP Probability Analysis}

Figure 2 illustrates the probability of respondents with WTP for the given amount when payment of the preservation fund was required for the perpetual existence of Wuyishan National Park. In general, as the given amount of the preservation fund increased, WTP decreased, correspondingly, which complied with economic principles. WTP proba- 
bility for Wuyishan National Park differed significantly between the hypothetical (71.9\%) and real $(64.2 \%)$ settings, indicating that some respondents did not express their genuine WTP in the hypothetical setting. The result supported the conclusion of prior studies that tourists' WTP in the real setting was lower than in the hypothetical setting [3,12]. It also verified that the design of the real setting could augment respondents' input into rational perception, reduce bias, and improve the reliability of WTP.

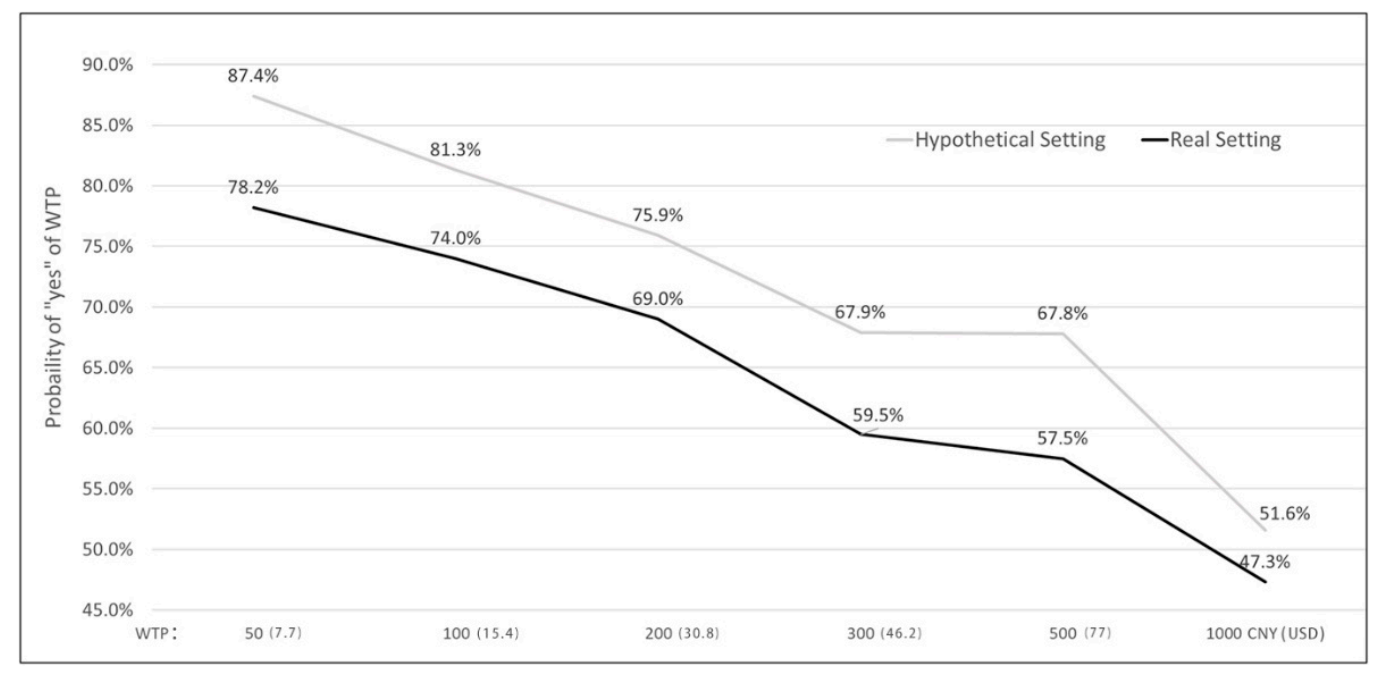

Figure 2. Probability of "yes" response of WTP in the hypothetical and real situation.

\subsection{Estimated Logit Model}

The result of the estimated Logit model is shown in Table 4. In the hypothetical and real settings, except for "away from daily life", other results were rather similar. In the real setting, "away from daily life" $(p<0.05)$ had a significant positive influence on WTP, but it was not so in the hypothetical setting, indicating that the stronger intention for getting away from daily life, the higher WTP of the respondents. In both settings, the given amount $(p<0.01)$ showed a significant negative impact on WTP, manifesting the higher the given amount, the lower WTP of the respondents. Importance of traditional culture $(p<0.01)$ and landscape structure $(p<0.05)$ exerted a significant positive effect on WTP, meaning that the respondents that better perceived the importance of traditional culture and better understood the Wuyishan landscape structure had higher WTP. Demographic variables had no significant influence on WTP in either setting, which proved that the respondents psychological statuses, consisting of their established values and experience processes, played an important role in estimating WTP, and supported the results validated by prior studies that tourists' cultural values [46] and experience activities $[48,49]$ had an influence on their willingness to pay. 
Table 4. Estimated Logit model.

\begin{tabular}{|c|c|c|c|c|c|c|c|c|}
\hline \multirow{2}{*}{ Variables } & \multicolumn{4}{|c|}{ Hypothetical Setting a } & \multicolumn{4}{|c|}{ Real Setting $b$} \\
\hline & $\beta$ & S.E. & $\mathbf{z}$ & $p$-Value & $\beta$ & S.E. & $\mathbf{z}$ & $p$-Value \\
\hline Given amount & -0.167 & 0.032 & 26.482 & 0.000 & -0.123 & 0.030 & 16.924 & 0.000 \\
\hline Revisit intention & 1.461 & 0.373 & 15.373 & 0.000 & 1.150 & 0.361 & 10.181 & 0.001 \\
\hline Gender & 0.130 & 0.227 & 0.329 & 0.566 & 0.046 & 0.203 & 0.050 & 0.822 \\
\hline Age & -0.102 & 0.110 & 0.869 & 0.351 & -0.047 & 0.101 & 0.219 & 0.640 \\
\hline Monthly income (per capita) & -0.038 & 0.103 & 0.139 & 0.710 & -0.039 & 0.092 & 0.176 & 0.675 \\
\hline Education & 0.114 & 0.276 & 0.170 & 0.680 & 0.015 & 0.244 & 0.004 & 0.951 \\
\hline Marital status & -0.092 & 0.246 & 0.141 & 0.707 & 0.061 & 0.221 & 0.075 & 0.785 \\
\hline Occupation & 0.078 & 0.066 & 1.402 & 0.236 & 0.028 & 0.059 & 0.219 & 0.640 \\
\hline $\begin{array}{c}\text { Familiarity with traditional } \\
\text { cultural symbols }\end{array}$ & 0.303 & 0.174 & 3.023 & 0.082 & 0.097 & 0.158 & 0.378 & 0.539 \\
\hline Importance of traditional culture & 1.090 & 0.291 & 14.025 & 0.000 & 0.855 & 0.268 & 10.206 & 0.001 \\
\hline Away from daily life & 0.219 & 0.195 & 1.257 & 0.262 & 0.430 & 0.181 & 5.663 & 0.017 \\
\hline Exploration and discovery & -0.325 & 0.298 & 1.189 & 0.276 & -0.412 & 0.276 & 2.221 & 0.136 \\
\hline Landscape structure & 0.324 & 0.139 & 5.447 & 0.020 & 0.288 & 0.130 & 4.941 & 0.026 \\
\hline Constant & -6.408 & 1.307 & 24.024 & 0.000 & -5.051 & 1.181 & 18.287 & 0.004 \\
\hline
\end{tabular}

a. Log likelihood $=391.404$, LR Chi-square $=69.536$, Cox and Snell $R^{2}=0.183$, Nagelkerke $R^{2}=0.248$. b. Log likelihood $=612.225$, LR Chi-square $=84.187$, Cox and Snell $R^{2}=0.146$, Nagelkerke $R^{2}=0.200$.

\subsection{Result of Estimated Non-Use Value}

As shown in Table 5, if WTP mean for the preservation value of Wuyishan National Park per household (per time) was taken as a benchmark; the estimated result was CNY 1117 (USD 172.2) in the hypothetical setting and CNY 1113 (USD 171.6) in the real setting. If WTP overall mean was taken as a benchmark, the result was CNY 1016 (USD 156.6) in the hypothetical setting and CNY 873 (USD 134.6) in the real setting; when WTP truncated was used as a benchmark, the result was CNY 693 (USD 106.8) in the hypothetical setting and CNY 609 (USD 93.9) in the real setting. In comparison with WTP truncated, overestimation was observed with both WTP mean and WTP overall mean. By the spatial scope of influence, tourists of Wuyishan National Park mainly came from the basic mark in Fujian Province and Jiangxi Province, and the key market in Beijing, Tianjin, and Hebei Province, Yangtze River Delta area, and Pearl River Delta area (Master Plan and Targeted Plan on Wuyishan National Park (2017-2025)). In the basic market (22,748,844 households), the aggregate preservation value of Wuyishan National Park depending on WTP truncated was CNY 15.8 million (USD 2.4 million) in the hypothetical setting and CNY 13.9 million (USD 2.1 million) in the real setting. In the key market $(146,178,160$ households), the aggregate preservation value depending on WTP truncated was 101.3 million CNY (\$15.6 million) in the hypothetical setting and CNY 89 million (USD 13.7 million) in the real setting. In the national market $(432,167,742$ households), the aggregate preservation value depending on WTP truncated was 299.5 million (USD 46.2 million) in the hypothetical setting and CNY 263.2 million (USD 40.6million) in the real setting. As shown in Table 6, Out of the three parts of preservation value, the respondents paid great and similar attention to existence value $(38.26 \%)$ and bequest value $(35.84 \%)$, but less attention to option value (25.9\%). 
Table 5. Results of estimated preservation value of Wuyishan in the two settings.

\begin{tabular}{|c|c|c|c|c|c|}
\hline & Category & Per Household & Basic Market $^{\text {a }}$ & Key Market ${ }^{\text {b }}$ & National Market $^{c}$ \\
\hline \multirow{3}{*}{$\begin{array}{l}\text { Hypothetical } \\
\text { setting }\end{array}$} & WTPmean & $\begin{array}{c}1117 \\
\text { (USD 172.2) }\end{array}$ & $\begin{array}{l}25.411 \text { million } \\
\text { (USD } 3.918 \text { million) }\end{array}$ & $\begin{array}{l}163.281 \text { million } \\
\text { (USD } 25.174 \text { million) }\end{array}$ & $\begin{array}{c}482.731 \text { million } \\
\text { (USD } 74.439 \text { million) }\end{array}$ \\
\hline & $\begin{array}{l}\text { WTPoverall } \\
\text { mean }\end{array}$ & $\begin{array}{c}1016 \\
\text { (USD 156.6) }\end{array}$ & $\begin{array}{l}23.112 \text { million } \\
\text { (USD } 3.564 \text { million) }\end{array}$ & $\begin{array}{c}148.517 \text { million } \\
\text { (USD } 22902 \text { million) }\end{array}$ & $\begin{array}{l}439.082 \text { million } \\
\text { (USD } 67.708 \text { million) }\end{array}$ \\
\hline & $\begin{array}{l}\text { WTP } \\
\text { truncated }\end{array}$ & $\begin{array}{c}693 \\
\text { (USD 106.8) }\end{array}$ & $\begin{array}{l}15.765 \text { million } \\
\text { (USD } 2.431 \text { million) }\end{array}$ & $\begin{array}{c}101.302 \text { million } \\
\text { (USD } 15.621 \text { million) }\end{array}$ & $\begin{array}{c}299.492 \text { million } \\
\text { (USD } 46.183 \text { million) }\end{array}$ \\
\hline \multirow{3}{*}{ Real setting } & WTPmean & $\begin{array}{c}1113 \\
\text { (USD 171.6) }\end{array}$ & $\begin{array}{l}25.319 \text { million } \\
\text { (USD } 3.904 \text { million) }\end{array}$ & $\begin{array}{c}162.696 \text { million } \\
\text { (USD } 25.089 \text { million) }\end{array}$ & $\begin{array}{l}481.003 \text { million } \\
\text { (USD } 74.173 \text { million) }\end{array}$ \\
\hline & $\begin{array}{l}\text { WTPoverall } \\
\text { mean }\end{array}$ & $\begin{array}{c}873 \\
\text { (USD 134.6) }\end{array}$ & $\begin{array}{l}19.860 \text { million } \\
\text { (USD } 3.062 \text { million) }\end{array}$ & $\begin{array}{c}127.613 \text { million } \\
\text { (USD } 19.67 \text { 9million) }\end{array}$ & $\begin{array}{l}377.283 \text { million } \\
\text { (USD } 58.179 \text { million) }\end{array}$ \\
\hline & $\begin{array}{l}\text { WTP } \\
\text { truncated }\end{array}$ & $\begin{array}{c}609 \\
\text { (USD 93.9) }\end{array}$ & $\begin{array}{l}13.854 \text { million } \\
\text { (USD } 2.136 \text { million) }\end{array}$ & $\begin{array}{c}89.023 \text { million } \\
\text { (USD } 13.726 \text { million) }\end{array}$ & $\begin{array}{c}263.190 \text { million } \\
\text { (USD } 40.585 \text { million) }\end{array}$ \\
\hline
\end{tabular}

Note: CNY (USD); RMB to U.S. dollar exchange rate: 6.49. ${ }^{\text {a }}$ : Basic market (Fujian Province and Jiangxi Province) with 22,748,844 households

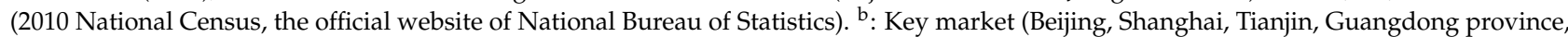
Zhejiang province, Jiangsu province, Hubei province, Hunan province, and Hebei province) with 146,178,160 households (2010 National Census, the official website of National Bureau of Statistics). ${ }^{c}$ : 432,167,742 households in total (2010 National Census, the official website of National Bureau of Statistics).

Table 6. Results of estimated three preservation value types based on WTP truncated.

\begin{tabular}{cccc}
\hline Value Type & $\begin{array}{c}\text { Existence Value } \\
\mathbf{( 3 8 . 2 6 \% )}\end{array}$ & $\begin{array}{c}\text { Option Value } \\
\mathbf{( 2 5 . 9 \% )}\end{array}$ & $\begin{array}{c}\text { Bequest Value } \\
\mathbf{( 3 5 . 8 4 \% )}\end{array}$ \\
\hline \multirow{2}{*}{ Hypothetical setting } & 11.457 million & 7.758 million & 10.734 million \\
& (USD 1.767 million) & (USD 1.196 million) & (USD 1.655 million) \\
\hline \multirow{2}{*}{ Real setting } & 10.069 million & 6.817 million & 9.433 million \\
& (USD 1.553 million) & (USD 1.051 million) & (USD 1.454 million) \\
\hline
\end{tabular}

Note: CNY (USD); With WTP truncated mean in the national market as the benchmark, the value of each value type is calculated through the respondents' distribution by ratio among the types.

In 2020, the central and provincial government allocated only CNY 64.99 million to the Administration for Wuyishan National Park (2020 Department Budget Statement of the Administration for Wuyishan National Park), meaning lower preservation input than the non-use value of the national park in the national market. According to Table 6, non-use value in the key market is six times that in the basic market and one-third of that in the national market. Accordingly, looking forward, Wuyishan National Park should adhere to the principle of "stabilizing the basic market and expanding the key market", to increase its non-use value.

\section{Conclusions}

Based on bounded rational decision making, this study conducted a questionnaire investigation among tourists of Wuyishan National Park with a two-stage approach of DC-CVM, and analyzed the respondents' WTP and preference by creating a Logit model, and estimated WTP with three methods, rather than veritably estimating the preservation value of the national park. The study came to the following conclusions:

1. The respondents' WTP was averaged at CNY 609 (based on WTP truncated, USD 93.9), quite close to the travel expense of tourists in reality. It is confirmed that during valuation based on two-stage DC-CVM, to estimate WTP by using WTP truncated reflected factual WTP, and further improved the two-stage DC-CVM.

2. In the hypothetical and real settings, the respondents' cultural worldview (importance of traditional culture) and perceived restorative environment (landscape structure) had significant influence on WTP, indicating the important role of individual psychological status in WTP. For the protection of national parks, it is necessary to take into 
consideration tourists' psychological status and WTP decision-making mechanism in the design of landscape and routes, to improve tourists' WTP for protection.

3. Compared with the estimated preservation value in the national market, actual public financial input into Wuyishan National Park was limited, which impeded the realization of synchronized and coordinated ecological balance of the national park, and social and economic development to some extent. Therefore, manifesting the preservation value of Wuyishan National Park has a positive effect on highlighting the importance of national parks and securing financial input. Meanwhile, the analysis results that the preservation value of the national parks in the key market was six times that in the basic market and one-third that in the national market provide decision-making basis for major market development of the national parks.

4. Out of the three parts of preservation value of national parks, the respondents believed more funds should be invested into protecting the parks' perpetual existence and bequest to later generations. It tells us that tourists' protection of Wuyishan National Park is not entirely based on personal utility, and building of the national park system has played a positive role in developing proper natural values. Thus, in the valuation of national parks, it is suggested to include sociological and anthropological discussions on altruism.

The results showed that, first, the use of two-stage DC-CVM could effectively avoid uncertainty with WTP decision making under bounded rationality and factually reflect the real WTP. The tourists showed a strong awareness of protection for Wuyishan National Park and a high WTP, and their psychological status exerted a major influence over WTP.

Objective intrinsic value of national parks is difficult to be measured by humanity with subjective preference from the perspective of utility. Non-use value as the result of measurement is merely a set of dynamic figures under balance with all stakeholders [43]. Therefore, in order to improve the human-centered valuation methods, instead of repeating the cycle of "bias observed $\rightarrow$ methods improved $\rightarrow$ methods complicated $\rightarrow$ new bias observed", it is admirable to face the existence of bias, straighten up the decision-making process in the valuation, and on such basis, explore effective methods of reducing the bias. Although the DC-CVM method is improved by the two-stage setting and its effectiveness has been verified by scholars in practice, the two-stage setting suffers from an unclear theoretical foundation. This study is based on bounded rational decision making, which responded to the theoretical applicability of the DC-CVM and extended the investigation scope of the DC-CVM, offering new insights into the improvement of current evaluation methods.

Holmes Rolston III held in his natural value theory that endowing other species with existence value by humanity reflected not only the utilization of others, but also altruism and ethical care of humanity [52]. In the valuation of public properties with high preservation value, neglection of their preservation value will result in the failure in manifesting their real value to humanity and giving corresponding "ethical care" to the properties as well as bring the threat to the threat to their perpetual existence. As a part of the value of national parks, use value reflected by the consumption of tourists is only a useful supplement, while the core value lies in keeping the ecosystem complete and protecting species and habitats, as in preservation value [53]. Therefore, how to increase the preservation value of national parks and manifest it to humanity is the key to their perpetual existence [4]. In the management of the establishment of national parks, it is important to remain human-centered and clarify the psychological status of tourists in travel and their WTP decision-making process. On such a basis, efforts should be stepped up accordingly in designing landscape and travel routes in the parks, planning for experience activities, and choosing promotion strategies to increase the WTP decision-making probability of tourists. Moreover, the selection of the target market has a major influence over the enhancement of national parks' preservation value. As a result, accurate marketing that starts from a basic market and centers on the key market is an effective way to increase the parks' preservation value. Therefore, the practical implication of this paper: first, to offer basic support for Wuyishan and other national parks in China to reasonably use protection funds, price 
tickets, input capital, and boost social involvement in the future. Second, in line with the tourists' preference, during formulation and implementation of national park policies, it is important to build up the concept of culture and tourism integration, further explore traditional cultural elements in the parks and embed cultural elements into natural tour experience, thereby enriching tourists' experience. Third, to manifest the preservation value of national parks is of great significance for developing proper natural values. In travel experience and activities, tourists cannot only realize the "win-win" relationship between greater involvement in the protection and better travel experience, but also better understand the value of ecological resources, thus participating more in the building of the national park system altruistically.

Existing research confirms that there are differences in the WTP among different types of respondents [2,3]. This paper also confirms that there are differences in the WTP of tourists from various source markets. However, as stated in the previous section on China's national park concept, the core of China's national parks lies in the protection of regional natural ecosystems and the cultural values attached to natural objects. Therefore, it is important to explore whether there is a difference in the value of WTP between 'nature-based' tourists and 'general' tourists. Due to the limited size of the questionnaire and the impact of COVID-19, it was not possible to distribute questionnaires in the field. The conduct lacked discriminant items of nature-based tourists and related interviews of ecological preferences about national parks. There are some limitations to the representativeness of the assessment results. With better conditions (in regards to the coronavirus pandemic) and the recovery of large-scale tourism in China, based on the results of this paper, we intend to explore the discriminant variables of nature-based tourists by means of interviews, and conduct the comparative analysis of WTP of different types of tourists through questionnaires, to explore a universal national park preservation value system while improving the study.

Author Contributions: C.L. designed and implemented the data analysis methods and wrote the manuscript. M.L. and X.Q. supervised the data analysis, participated in writing, and revised the manuscript. W.Z. assisted with the data analysis and manuscript preparation. All authors have read and agreed to the published version of the manuscript.

Funding: This research was funded by the project of National Natural Science Foundation of China (grant nos. 41601590 and 41971261), the National Social Science Fund of China (grant no. 19CDJ033), the Natural Science Foundation of Fujian province of China (grant no. 2019J01430), China Mindong Tourism Poverty Alleviation Research Center 2020 Open Project (grant no. EFTPARC202001), 2020 Fujian provincial Department of Science and Technology middle-aged and Young People Project (grant no. JAS19049).

Institutional Review Board Statement: Not applicable.

Informed Consent Statement: Not applicable.

Data Availability Statement: The data presented in this study are available on request from the corresponding author. The data are not publicly available due to the raw data required to reproduce these findings cannot be shared at this time as the data also forms part of an ongoing study.

Conflicts of Interest: The authors declare no conflict of interest.

\section{References}

1. Freeman, A.M. The Measurement of Environmental and Resource Value: Theory and Methods; Resources for the Future: Washington, DC, USA, 1993.

2. Lee, C.K.; Han, S.Y. Estimating the use and preservation values of national parks' tourism resources using a contingent valuation method. Tour. Manag. 2002, 23, 531-540. [CrossRef]

3. Jin, M.; Juan, Y.; Choi, Y.; Lee, C.K. Estimating the Preservation Value of World Heritage Site Using Contingent Valuation Method: The Case of the Li River, China. Sustainability 2019, 11, 1100. [CrossRef]

4. He, S.Y.; Su, Y.; Wang, L.; Cheng, H.G. Realisation of recreation in national parks: A perspective of ecosystem services demand and willingness to pay of tourists in Wuyishan Pilot. J. Nat. Res. 2019, 34, 40-53.

5. Li, M.; Wu, B.; Cai, L. Tourism development of World Heritage Sites in China: A geographic perspective. Tour. Manag. 2008, 29, 308-319. [CrossRef] 
6. Poria, Y.; Reichel, A.; Cohen, R. Tourists perceptions of World Heritage Site and its designation. Tour. Manag. 2013, 35, $272-274$. [CrossRef]

7. Harvey, F. Statue of Liberty and Venice among Sites at Risk from Climate Change, Says UN, The Guardian, 2016. Available online: https:/ / www.theguardian.com/environment/2016/may/26/statue-of-liberty-venice-climate-change-threat-un-report (accessed on 28 May 2016).

8. Song, B. The mutual relationship among National Park and the indigenous people between U. S. A and Canadian. J. Nat. Park 2001, 11, 96-114.

9. Dorbeiki, M.; Moharramnejad, N.; Rahnamai, M.; Taqi, M.; Mazdak, D. Application of a'wot method in strategic management of sustainable tourism in a national park. Environ. Eng. Manag. J. 2017, 16, 471-480. [CrossRef]

10. Kim, S.S.; Wong, K.K.; Cho, M. Assessing the economic value of a world heritage site and willingness-to-pay determinants: A case of Changdeok Palace. Tour. Manag. 2007, 28, 317-322. [CrossRef]

11. Choi, A.S.; Ritchie, B.; Papandrea, F.; Bennett, J. Economic valuation of cultural heritage sites: A choice modeling approach. Tour Manag. 2010, 31, 213-220. [CrossRef]

12. Ji, S.; Choi, Y.; Lee, C.; Mjelde, J. Comparing willingness-to-pay between residents and non-residents using a con-tingent valuation method: Case of the Grand Canal in China. Asia Pacif. J. Tour. Res. 2018, 23, 79-91. [CrossRef]

13. Bishop, R.C.; Heberlein, T.A. Measuring Values of Extramarket Goods: Are Indirect Measures Biased? Am. J. Agric. Econ. 1979, 61, 926-930. [CrossRef]

14. Hanemann, W.M. Valuing the Environment Through Contingent Valuation. J. Econ. Perspect. 1994, 8, 19-43. [CrossRef]

15. Robert, L.G. Intuition's role in decision making. IEEE Software 2008, 25, 95-96.

16. Simon, H.A. Administrative Behavior: A Study of Decision-Making Processes in Administrative Organizations, 4th ed.; Free Press: New York, NY, USA, 1997.

17. Oliver, F. Rationality Concepts in Environmental Valuation; Peter Lang D: Bern, Switzerland, 2018.

18. Pan, Y.; Marshall, S.; Maltby, L. Prioritising ecosystem services in Chinese rural and urban. Communities. Ecosyst. Serv. 2016, 21, 1-5. [CrossRef]

19. Protected Planet Report. 2020. Available online: https:/ /livereport.protectedplanet.net/ (accessed on 20 March 2021).

20. General Program for the Establishment of National Park System. 2017. Available online: http://www.gov.cn/zhengce/2017-09/ 26/content_5227713.htm (accessed on 8 October 2017).

21. Cao, H.; Lin, S.; Zhang, J.; Cao, A.; Chen, W.; Yan, S. Welfare value and heterogeneity: An experimental analysis of tour-ists'choice Wuyishan national park. J. Ecol. Rural Environ. 2021, 1-13. [CrossRef]

22. Wang, Z.F.; Shi, M. Evaluation of national park management effectiveness based on SE-DEA: A case study of ten national parks system. Mount. Res. 2020, 38, 93-104.

23. Pai, C.K.; Wang, Z.Y.; Chen, S.H. Measuring the effect of ubiquitous internet success on traveler' perceived value and overall tourism destination satisfaction. Int. J. Tour. Sci. 2017, 17, 298-315. [CrossRef]

24. Chiu, Y.-T.H.; Lee, W.-I.; Chen, T.H. Environmentally responsible behavior in ecotourism: Antecedents and implications. Tour. Manag. 2014, 40, 321-329. [CrossRef]

25. Dou, L. Tourists' perceived value, satisfaction and environmental-responsibility behavior. J. Arid. Land Resour. Environ. 2016, 30, 197-202.

26. Yu, Y.; Tian, J.X.; Shu, J. A study on the relation of place dependence and tourists' post-tour behavioral preference-with value perception, and satisfactory experience as the media variable. Tour. Sci. 2010, 24, 54-62.

27. Lee, C.K.; Mjelde, J.W. Valuation of ecotourism resources using a contingent valuation method: The case of the Korean DMZ. Ecol. Econ. 2007, 63, 511-520. [CrossRef]

28. Lee, C.K. Valuation of eco-tourism resources for DMZ using a contingent valuation method: International comparison of values. Int. J. Tour. Hosp. Res. 2005, 17, 65-81.

29. Lin, Y.C. The willingness of heritage tourists to pay for perceived authenticity in Pingxi, Taiwan. Curr. Issues Tour. 2015, 20, 1044-1069. [CrossRef]

30. Lee, D.E.; Jin, M.L.; Lee, C.K. Estimating the economic value of Hallyu experience using CVM-valuation of Hallyu for Chinese tourists. Kor. J. Tour. Res. 2015, 30, 163-182.

31. Mjelde, J.W.; Kim, H.; Kim, T.-K.; Lee, C.-K. Estimating Willingness to Pay for the Development of a Peace Park Using CVM: The Case of the Korean Demilitarized Zone. Geopolitics 2017, 22, 151-175. [CrossRef]

32. Hensher, D.A.; Rose, J.M.; Greene, W.H. Applied Choice Analysis, 2nd ed.; Cambridge University Press: Cambridge, UK, 2015.

33. Dias, V.; Belcher, K. Value and provision of ecosystem services from prairie wetlands: A choice experiment approach. Ecosyst. Serv. 2015, 15, 35-44. [CrossRef]

34. Miller, S.; Peter, T.; Caroline, S. Estimating indigenous cultural values of freshwater: A choice experiment approach to Māori values in New Zealand. Ecol. Econ. 2015, 118, 207-214. [CrossRef]

35. Mazzotta, M.J.; Opaluch, J.J. Decision making when choices are complex: A test of Heiner's hypothesis. Land Econ. 1995, 71, 500-515. [CrossRef]

36. Arrow, K.; Solow, R.; Portney, P.; Leamer, E.; Radner, R.; Schuman, H. Report of the NOAA Panel on contingent valuation. Fed. Reg. 1993, 58, 4601-4614. 
37. Johannesson, M.; Liljas, B.; Johansson, P.-O. An experimental comparison of dichotomous choice contingent valuation questions and real purchase decisions. Appl. Econ. 1998, 30, 643-647. [CrossRef]

38. Lee, C.-K.; Kim, T.-K.; Mjelde, J.W. Comparison of preservation values between Internet and interview survey modes: The case of Dokdo, South Korea. J. Environ. Plan. Manag. 2014, 59, 22-43. [CrossRef]

39. Kim, J.Y.; Mjelde, J.W.; Kim, T.K.; Ahn, K.M. Comparing willing-to-pay between residents and non-residents when correcting hypothetical bias: Case of endangered spotted seal in South Korea. Ecol. Econ. 2012, 78, 123-131. [CrossRef]

40. Kang, S.K.; Lee, C.K.; Lee, D.-E. Examining Cultural Worldview and Experience by International Tourists: A Case of Traditional House Stay. Asia Pacif. J. Tour. Res. 2016, 21, 477-499. [CrossRef]

41. Lee, Y.K.; Lee, C.K.; Choi, J.; Yoon, S.M.; Hart, R.J. Tourism's role in urban regeneration: Examining the impact of environ-mental cues on emotion, satisfaction, loyalty, and support for Seoul's revitalized Cheonggyecheon stream district. J. Sustain. Tour. 2014, 22, 726-749. [CrossRef]

42. Toelken, B. Cultural worldview. In Dynamics of Folklore, revised and expanded ed.; Toelken, B., Ed.; Utah State University Press: Logan, UT, USA, 1996; pp. 263-313.

43. Hewitt, D. A Clash of Worldviews: Experiences from Teaching Aboriginal Students. Theory Pract. 2000, 39, 111-117. [CrossRef]

44. Choi, A.S.; Papandrea, F.; Bennett, J. Assessing cultural values: Developing an attitudinal scale. J. Cult. Econ. 2007, 31, 311-335. [CrossRef]

45. Lehto, X.Y. Assessing the Perceived Restorative Qualities of Vacation Destinations. J. Travel Res. 2012, 52, 325-339. [CrossRef]

46. Douglas, O.; Lennon, M.; Scott, M. Green space benefits for health and well-being: A life-course approach for urban planning, design and management. Cities 2017, 66, 53-62. [CrossRef]

47. Arbelo, K.; Delgado, N.; Ruiz, C.; Hernández-Fernaud, E. The role of perceived restorative capacity and crowding on satisfaction: A study in different tourist spaces (El papel de la capacidad restauradora percibida y el hacinamiento sobre la satisfacción: Un estudio en diferentes espacios turísticos). Int. J. Soc. Psychol. 2021, 36, 265-299. [CrossRef]

48. Hartig, T.; Kaiser, F.G.; Bowler, P.A. Further Development of a Measure of Perceived Environment Restorativeness (Working Paper No. 5); Uppsala University, Institute for Housing Research: Gavle, Sweden, 1997; Volume 5, pp. 1-19.

49. Laumann, K.; Gärling, T.; Stormark, K.M. Rating scale measures of restorative components of environments. J. Environ. Psychol. 2001, 21, 31-44. [CrossRef]

50. Pals, R.; Steg, L.; Siero F, W. Development of the PRCQ: A measure of perceived restorative characteristics of zoo attractions. J. Environ. Psychol. 2009, 29, 441-449. [CrossRef]

51. Han, S.Y.; Lee, C.K. Estimating the value of preserving the Manchurian black bear using the contingent valuation method. Scand. J. Forest Res. 2008, 23, 458-465. [CrossRef]

52. Rolston, H., III. Environmental Ethics Duties to and Values in the Natural World; Temple University Press: Philadelphia, PA, USA, 1988.

53. Butler, R.; Boyd, S. Tourism and National Parks: Issues and Implications; Wiley: Hoboken, NJ, USA, 2002. 